\title{
A Look Back to Move Ahead: New Directions for Research on Proactive Performance and Other Discretionary Work Behaviours
}

\author{
Doris Fay* \\ University of Potsdam, Germany \\ Sabine Sonnentag \\ University of Konstanz, Germany
}

\begin{abstract}
Over the last two decades, the multi-dimensional notion of job performance has been fully brought to life. The differentiation between core task performance and various aspects of discretionary work behaviour is now commonly applied. A multitude of empirical studies, enhancing our knowledge of the antecedents and consequences of the different performance aspects, have recently been summarised through various meta-analyses. We use this as an occasion for taking stock in order to identify new areas of theorising and empirical research. Focusing in particular on proactive performance aspects, the present paper identifies three themes that could inspire new research and model development. We suggest taking a new approach to the treatment of time in order to account for the dynamic nature of performance on the one hand, and to consider life-span changes on the other, developing comprehensive models on proactivity-enhancing interventions, and more strongly incorporating a crosscultural perspective.
\end{abstract}

Durant les deux dernières décennies, la notion multidimensionnelle de performance au travail a été portée sur le devant de la scène. La différence entre la performance centrale dans la tâche et divers aspects de la conduite intentionnelle au travail est désormais entrée dans les esprits. Une multitude d'études empiriques qui enrichissent nos connaissances sur les antécédents et les conséquences des multiples facettes de la performance ont récemment été globalisées dans plusieurs méta-analyses. Nous les exploitons afin d'ouvrir de

* Address for correspondence: Doris Fay, University of Potsdam, Karl-Liebknecht-Str. 24-26, 14476 Potsdam OT Golm, Germany. Email: doris.fay@uni-potsdam.de

We thank Ruth Kanfer and Paul Spector for very helpful comments on an earlier version of this paper. 
2

nouveaux champs recherches théoriques et empiriques. En se focalisant en particulier sur les dimensions proactives de la performance, cet article identifie trois thèmes qui pourraient inspirer de nouvelles recherches et favoriser le développement de nouveaux modèles. On propose de traiter le temps différemment afin de prendre en compte d'une part le caractère dynamique de la performance et d'autre part les changements au cours de la vie, de développer des modèles exhaustifs des interventions améliorant la proactivité, et d'intégrer plus étroitement la perspective transculturelle.

\section{INTRODUCTION}

Understanding the nature and determinants of job performance is a central field of interest in applied psychology. Even though it has long been acknowledged that "performance is often, if not typically, multidimensional" (Schmidt \& Kaplan, 1971, p. 421), until the 1980s, research tended to focus on one performance aspect only. Studies exploring the performance of core tasks of a job dominated the field. The advent of organisational citizenship behaviour (OCB) (Organ, 1988; Smith, Organ, \& Near, 1983), prosocial behaviour (Brief \& Motowidlo, 1986), contextual performance (Borman \& Motowidlo, 1993), personal initiative (Frese, Kring, Soose, \& Zempel, 1996), and related constructs, as well as the emergence of context-specific behaviours (e.g. proactive feedback seeking; Ashford \& Cummings, 1983) finally brought the notion of multidimensionality to life. The field experienced a proliferation of partly overlapping constructs of discretionary work behaviour, including not only desirable behaviours (e.g. OCB, proactive work behaviour) but also voluntary but undesirable behaviours. The latter type, often summarised as deviant or counterproductive work behaviour, encompasses actions that violate norms and thus represent a threat to other members of the organisation, or that have the potential to harm the organisation itself (theft, substance use, absenteeism, aggression) (Sackett, 2002; Skarlicki \& Folger, 1997). Today, research groups in organisational behaviour and related fields empirically differentiate between various broad aspects of performance; while some distinguish between task performance, organisational citizenship behaviours, and counterproductive work behaviours (Rotundo \& Sackett, 2002) (cf. Dalal, 2005), others suggest that work role performance comprises proficiency, adaptability, and proactivity (M.A. Griffin, Neal, \& Parker, 2007).

Recent meta-analyses demonstrate that differentiating between the various performance aspects is fruitful. The construct validity of the different performance aspects is now well established: a number of meta-analyses have explored the relationship between the different performance aspects (Dalal, 2005; Hoffman, Blair, Meriac, \& Woehr, 2007), have shed more light on the specific performance components (e.g. altruism, sportsmanship, civic virtue) that are included in the larger performance aspects (e.g. OCB) (Berry, Ones, \& Sackett, 2007; LePine, Erez, \& Johnson, 2002; Tornau \& Frese, 2009), 
and have looked into the consequences of discretionary performance (N.P. Podsakoff, Whiting, Podsakoff, \& Blume, 2009). Other meta-analyses have studied antecedents at the level of job attitudes (Fassina, Jones, \& Uggerslev, 2008), leadership behaviours (Ilies, Nahrgang, \& Morgeson, 2007), and the work situation (Hershcovis, Turner, Barling, Arnold, Dupré, Inness, LeBlanc, \& Sivanathan, 2007).

This almost unprecedented number of meta-analyses on performance concepts provides an excellent starting point for taking stock of past research approaches and their findings. Building upon these, the present article identifies three areas that we believe deserve more research attention. They relate to the temporal perspective taken in research on discretionary work behaviours, to interventions, and to cultural issues. When developing those potential research areas we focus in particular on how they will further our understanding of proactive behaviours. We want to point out that focusing on proactive behaviour is motivated more by our personal interests than by the assumption that other discretionary work behaviours are less important. We also want to clarify that we concentrate on conceptualisations of behaviour (e.g. taking charge, personal initiative, proactive behaviour, or voice), paying less attention to trait-like approaches (e.g. proactive personality; Bateman \& Crant, 1993). When developing those areas we show how the papers of the present special issue fit into the proposed research topics. The three areas and the related research suggestions we present are not by any means exhaustive. Instead, they represent a selection of topics that we feel have a high potential to further theory development and empirical research; some of the proposed research approaches might result in counterintuitive findings that will challenge our current thinking.

Even though the cited meta-analyses have provided more than sufficient evidence of the distinctness of many individual discretionary work behaviour constructs, for ease of communication, we will in many places not distinguish between them but apply the term "discretionary work behaviour" (DWB) (and we will also include both desired and undesired behaviours).

\section{EXPANDING OUR TIME PERSPECTIVE}

Research on DWB would benefit from taking new approaches to time. First, taking the dynamic nature of work behaviour into account, DWB should be explored within smaller time frames using episodic approaches; second, we should take the particular stage of an actor's lifetime into consideration. We consider both perspectives now in turn.

\section{Moving to Episodic Approaches}

Since the publication of the early (typically cross-sectional) studies on DWB, we have seen an increase in longitudinal studies (e.g. Hakanen, Perhoniemi, \& 
Toppinen-Tanner, 2008; Hornung \& Rousseau, 2007; N.P. Podsakoff et al., 2009). The advantage of a longitudinal approach is - provided an appropriate time frame has been chosen and there is sufficient change in the variables- that it can provide reasonably strong data that imply fewer causal ambiguities then than do cross-sectional data. But there are also limitations regarding the insights they can provide. Due to the time frame studied-typically several months up to three years (e.g. Frese, Garst, \& Fay, 2007; Hakanen et al., 2008) -insights into the dynamics of individual performance episodes cannot be captured. For example, Beal, Weiss, Barros, and MacDermid (2005) have argued that performance differs not only between, but also within persons, because employees do not always perform at a constant level. This fluctuation is of interest as it cannot be attributed to random processes; instead, it seems to be caused by systematic variations in other variables such as affective experiences and affect regulation. Empirical evidence supports this view. Substantial systematic within-person variability has been observed for task performance (Fisher \& Noble, 2004; Trougakos, Beal, Green, \& Weiss, 2008), OCB (Ilies, Scott, \& Judge, 2006), and proactive behaviours such as personal initiative (Binnewies, Sonnentag, \& Mojza, 2009; Sonnentag, 2003).

What new insights could an episodic approach deliver? It might reveal relationships among the performance aspects that are different from what is identified when using a longer time frame. Meta-analyses have revealed that desirable performance aspects are positively interrelated and that they are negatively related to undesired performance aspects (Dalal, 2005; Hoffman et al., 2007; Tornau \& Frese, 2009). Looking at the task performance-DWB link with an episodic approach that captures the performance of both activities within smaller time frames might reveal a different pattern. We illustrate this idea using personal initiative (PI) as an example from the proactive performance category. Personal initiative has been defined as proactive, selfstarting and persistent behaviour (Frese \& Fay, 2001). Consider a call-centre employee who receives several complaints about ambiguous purchase instructions placed on a recently launched company's website; the employee might try to follow up on this problem and get it improved. While trying to identify the colleagues who can implement the changes on the website, s/he will be able to take fewer calls and thus the work records will indicate lower task performance. In such a case the assessment of PI and task performance in a given week or on a given day would result in a negative relationship. As PI fluctuates substantially from day to day, bouts of PI are probably associated with low levels of task performance, followed by phases of low PI and high levels of task performance.

Another mechanism that could lead to a temporary negative link between PI and task performance originates from PI's potential to change work tasks. Consider a university secretary whose job it is to keep scientific staffs' websites up to date. To this end, each quarter s/he collects data on new publica- 
tions, grants, or projects, and sends the information to the web administrator with detailed instructions on where to enter the data. After the amendments have been implemented, the secretary checks whether changes have been appropriately done, and the same procedure starts again after three months. To avoid this laborious process, s/he takes the initiative to get a content management system implemented that permits that her/him to enter the data directly. Before $s /$ he can perform this job efficiently, s/he will have to get practice; and with increasing experience the process will become more efficient. In this case, PI leads to changes in the secretary's work demands; with the consequence that task performance can be reduced temporarily because time needs to be afforded to learn new skills.

An episodic approach could support the development of models on DWB that take the specific context or situation of an organisation into account. Some authors have suggested that DWB can be organised along the dimension of challenging versus protecting the status quo (Van Dyne, Cummings, \& Parks, 1995). While the challenging (e.g. voice, PI) and protecting behaviours (e.g. helping, $\mathrm{OCB}$ ) are positively interrelated when assessed at a chronic level (Stampler \& Van Dyne, 2001; Van Dyne \& LePine, 1998), consideration of a specific context and use of an episodic approach might reveal a different pattern. Here, we consider the context of change necessity. One ubiquitous challenge for contemporary organisations is that they have to change and adapt to the increasingly dynamic environment. This development implies that work processes or procedures become dysfunctional rather quickly. Employees can respond to dysfunctional procedures in various ways: they can leave the procedure as it is and demonstrate high levels of sportsmanship, extra-effort and altruism, such that the organisation can carry on as hitherto. A different way of responding would be to push the organisation to overcome their inertia and change things for the better. Someone not ready to put up with the old system might take the initiative to change the system. This could involve refusing to help colleagues who exhibit behaviours that let the old system survive. Devoting energy to changing the system might go along not only with low altruism but also with low sportsmanship. While PI and OCB, and other challenging and protective behaviours, are positively related when assessed as chronic behavioural tendencies (Stampler \& Van Dyne, 2001; Van Dyne \& LePine, 1998), the relationship between the two types of constructs could be negative in specific contexts; this pattern emerges only when looking at smaller time lags between measurements.

A different temporal approach can also provide some refinement on the link between positive and negative performance aspects. A meta-analysis demonstrated that there is a moderate but significant negative relationship between citizenship behaviours and CWB (Dalal, 2005). Spector and Fox (2010, this issue) present a model that identifies circumstances where the linkage between OCB and CWB might be positive. Uncovering the proposed 
positive association depends, however, on a change of the time frame in which OCB and CWB would be studied; the use of an episodic approach in future studies would be conducive for this purpose.

\section{Introducing a Life-Span Approach}

Numerous studies have been dedicated to identifying personal and contextual antecedents of DWB (cf. the meta-analyses by Fassina et al., 2008; Hershcovis et al., 2007; Tornau \& Frese, 2009). Building upon insights into the traits, attitudes, motives, and values that seem to underlie DWB (Rioux \& Penner, 2001), the next step in this area should take employees' specific life-stage into account. Theories on life-span development imply that goals, values, and motives change over life. Socioemotional selectivity theory, for example, implies that motives change across adulthood because goals around affect are reorganised (Carstensen, Isaacowitz, \& Charles, 1999). Similarly, stage approaches to career suggest that people are preoccupied with different themes in their life depending on the career stage (Super, 1990). Research that explores the relationship between age and values or motives suggests that what people value and what motivates them might change over their life (Warr, 2008) (cf. Kanfer \& Ackerman, 2004). This implies that the nature of DWB may change over the lifetime such that what motivates DWB when people are in an early career stage (e.g. during exploration) may be different from what motivates DWB in later career stages (e.g. during the maintenance or decline stage; cf. Super, 1990). For example, a faculty member of a university might initiate a project group that develops a structured $\mathrm{PhD}$ programme. At an early career stage, this PI might be motivated by a desire to grow and expand one's skills, and at later career stages it could be motivated by the desire to mentor younger colleagues. In other words, what appears to be the same behaviour at an observable level can be driven by different factors depending on the career stage.

At the other end of the worklife continuum, Kanfer, Wolf, Kantrowitz, and Ackerman (2010, this issue) examine the determinants of performance during young adulthood as a function of context. Using a within-person methodology that holds the person constant across performance settings, they evaluated the predictive validities of a wide range of ability and nonability trait complexes on academic and initial job performance. Their results show that individual differences in non-ability traits made a significant contribution to both academic and overall job performance, beyond that of cognitive abilities. Of particular interest is the finding that individual differences in social orientation/communion traits played a significant role in predicting non-technical job performance, but not academic performance. As they suggest, social traits that promote proactive work behaviours may be particularly important in entry-level ratings of job performance, when DWBs 
are often viewed by supervisors as key positive indicators of the individual's fit to the job and organisation.

Extending research on DWB with a life-span perspective seems to be a fruitful avenue for future research. When trying to generalise findings on proactive behaviour across different age groups we have to be aware that the patterns of predictors and outcome variables may change over the life course. Future research that assumes a life-span perspective will have to be committed to a longitudinal approach with long time lags. A cross-sectional approach - even though likely to deliver interesting insights into cohortbased effects-does not allow sound inferences on intra-individual changes.

\section{ENHANCING DWB THROUGH INTERVENTIONS}

Even though DWBs have been demonstrated to contribute to individual performance, organisational performance (N.P. Podsakoff et al., 2009; Tornau \& Frese, 2009), and career success (e.g. Allen, 2006), there are only a few studies that report interventions that seek to enhance specific components of DWB. Considering the role that both scholars and practitioners have assigned to DWB for successful performance in an increasingly changing and complex work context (Campbell, 2000; Frese, 2008; Koys, 2001; P.M. Podsakoff, Ahearne, \& MacKenzie, 1997), the development of parsimonious models of interventions appears timely.

On a very general level, interventions can build upon two different strategies. The first strategy, a more distal approach, seeks to enhance the target behaviour indirectly by changing factors that support or hinder its development. One common distal approach refers to job design. The second strategy is of a comparatively more proximal nature; it seeks to directly enhance the desired behaviour or its immediate antecedents. The typical approach to the latter is training. We now briefly explore the types of interventions in turn and explore implications for model building.

\section{Intervention I: A Call for Developing Models on Changing Distal Variables}

The first strategy — change of distal variables - seeks to enhance factors that have been consistently identified to benefit DWB. So far, the few interventions for proactive behaviours that we have been able to identify built upon job redesign. For example, one workplace variable that has repeatedly been shown to benefit proactive behaviours is job autonomy (Frese, Garst et al., 2007; Ohly, Sonnentag, \& Pluntke, 2006; Parker, Wall, \& Jackson, 1997; Parker, Williams, \& Turner, 2006). Accordingly, a job design approach that involves expanding job holders' job autonomy increases a proactive work role (Axtell \& Parker, 2003; Parker et al., 1997). 
Although interventions which are rooted in a traditional job design approach have proven to be fruitful, they have been limited as they have not yet considered the whole breadth of potential intervention points. In addition to job autonomy, leadership variables (Belschak \& Den Hartog, in press; Rank, Carsten, Unger, \& Spector, 2007) and climate-related factors (LePine et al., 2002; LePine \& Van Dyne, 1998; Parker et al., 2006) have been shown to predict proactive behaviour. In the future, it is important to consider more workplace and contextual factors in order to enhance DWB successfully. We anticipate, however, that expanding the scope of target variables will involve two problems: first, there might be dilemmas, and second, there might be effective routes to take that we have not yet thought of.

Dilemmas in interventions may develop when a change of factors that benefit DWB has undesired side effects. There is increasing evidence that workplace stressors have a positive effect on PI and other proactive behaviours. In a longitudinal study, time pressure and organisational problems predicted increases in personal initiative (Fay \& Sonnentag, 2002); other studies also suggest a positive effect of time pressure on proactive behaviours (Ohly et al., 2006). From the perspective of intervention, these findings suggest that we should increase time pressure to bring about proactive behaviours; otherwise, at least ignore high levels of time pressure in an intervention that aims at increasing proactive behaviour. This obviously runs counter to insights from stress research that demonstrated the negative effects of time pressure (de Lange, Taris, Kompier, Houtman, \& Bongers, 2003; Sonnentag \& Frese, 2003). A recent meta-analysis confirms this dilemma: results indicate that time pressure (conceptualised as a challenge stressor) is related to strain symptoms even though it is also associated with higher work motivation (N.P. Podsakoff, LePine, \& LePine, 2007). Similarly, using work routines as a point of intervention may also cause a dilemma. A study with engineers showed that routines were associated with higher levels of proactive behaviours (Ohly et al., 2006). Increasing routines, however, may cause boredom. Thus, in order to reap the potential benefits of DWB we need models that systematically incorporate potential side effects on other relevant outcomes such as job attitudes and well-being, and also consider short- and long-term effects.

A second challenge towards distal interventions is that interventions might target input factors that are not the most effective ones. For example, counterproductive work behaviours have been identified as a response to workplace stressors (Fox, Spector, \& Miles, 2001). The implication of this finding would be to remove the stressor. The results of Semmer, Tschan, Meier, Facchin, and Jacobshagen (2010, this issue), however, suggest another promising avenue. To understand causes of CWB they explored the role of "illegitimate tasks". Illegitimate tasks are defined as tasks and demands that violate the norms about what can reasonably be expected from a work role. 
What is "illegitimate" is highly dependent on the work role. A PhD student's request to the supervisor to mark typos and spelling mistakes when reading the student's research proposal is likely to be regarded as illegitimate, while the same request directed to a professional proofreader would be fully appropriate. The results of Semmer et al. demonstrate that illegitimate task performance is positively related to CWB. In other words, employees are more likely to respond with CWB when approached with requests that violate their expectations and thus insult their work identity. Furthermore, the results also indicate that illegitimate tasks enhance CWB above and beyond the effects of other, more "traditional" workplace stressors. From the perspective of an intervention - in this case, to decrease CWB - this result points to two challenges. First, based on our knowledge that CWB covaries (among other things) with workplace stressors, an intervention is most likely to focus on reducing the stressors that we would typically associate with a job (e.g. heat, danger, or lack of information during an emergency for a fire-fighter). This, however, may not be the only and not the most effective way of reducing CWB. Reducing illegitimate tasks may be as effective. Unfortunately, illegitimate tasks are not (yet) on our "map" of interventions and may thus escape our attention. Second, the relational nature of the concept of "illegitimate" requires the development of job-specific tools of assessment.

\section{Intervention II: Changing Proximal Variables and the Behaviour Itself}

The second intervention approach relates to strategies that enhance proximal predictors of the target behaviour or that seek to directly increase the target behaviour. Regarding proactive behaviour, we have been able to identify only a small number of training interventions. They have been tailored to the needs of unemployed people (Frese, Garman, Garmeister, Halemba, Hortig, Pulwitt, \& Schildbach, 2002) and students (Kirby, Kirby, \& Lewis, 2002), or they were designed as a method to ultimately reduce strain (Bond \& Bunce, 2000; Searle, 2008).

When designing training, a decision has to be made about how to develop rather general knowledge and skills that promote proactive behaviour applicable across a wide range of situations. The reason for this is that the field has seen the development of a considerable number of specific, contextdependent proactive behaviour constructs. For example, there is proactive feedback seeking (Ashford \& Black, 1996), proactive retirement preparation (B. Griffin \& Hesketh, 2008), or developmental proactivity (van Veldhoven \& Dorenbosch, 2008); other proactive behaviour constructs are job specific like proactive customer service (Rank et al., 2007). Considering the wide breadth of different jobs in which proactive behaviours are desirable, it might not be very effective to develop job-specific and context-specific proactivity 
training for all the relevant domains. Therefore, having a training concept that is sufficiently generic to be useable for training interventions regardless of the specific job or target population appears a highly attractive idea. We suggest that proactivity training that builds upon the principles of teaching proactivity-relevant self-management or self-regulation skills might be sufficiently generic to serve different purposes.

The construct of personal initiative appears to be a suitable one from which to derive self-management principles. For example, skills that relate to personal goal setting and to the maintenance of persistence during goal pursuit should be relevant for the development of PI. More specifically, when pursuing a self-set goal, activities will often be associated with setbacks and failures. What self-regulation skills underlie those proactive behaviours so that they can be performed effectively? Emotion control skills should be associated with higher frequency of initiative taking as they help to tolerate rejection of one's ideas. Thus, as PI comprises various interacting facets, PI offers various starting points for training. One successful example has been developed in the area of career management. Using action regulation theory (Frese \& Zapf, 1994; Hacker, 1986) and the principles of self-management, Raabe and colleagues developed training that enhanced career selfmanagement behaviours that help to take the initiative regarding one's career (Raabe, Frese, \& Beehr, 2007).

Self-management training, first developed in clinical psychology and extensively applied there (Karoly \& Kanfer, 1982), has also been used in the work setting (Frayne \& Geringer, 2000; Latham \& Frayne, 1989). One advantage is that self-management strategies might benefit performance in other settings that also require personal initiative, such as in learning. Support for this notion is provided by Kanfer and her colleagues (2010, this issue) who found that individual differences in self-management explained variance in academic performance beyond that of cognitive abilities.

Another indicator for the effectiveness of a training approach based on self-management derives from a specific training strategy focusing on active/ exploratory training. Training approaches vary considerably in the amount of activity that they demand from the learner (Aguinis \& Kraiger, 2009). In conventional guided training, the trainer makes sure that the learner learns the correct way of mastering the task step by step, that s/he enlarges the knowledge in a systematic way. Here, the learner is a passive recipient of instructions and, consequently, of structured insights. This is in contrast to active/exploratory training, in which the learner receives minimal information on how to solve the tasks. This method relies strongly on the learner becoming an active explorer of the task domain so that they can identify the solutions on their own (Bell \& Kozlowski, 2008). A meta-analysis on the effectiveness of one type of active/exploratory training - error management training - substantiates its effectiveness (Keith \& Frese, 2008). 
Keith, Richter, and Naumann explored the effect of individual difference variables on the effectiveness of the two types of training (2010, this issue). They found that persons low on cognitive ability and low on motivation fare better (in terms of transfer performance) in active/exploratory training in comparison to guided training. The authors suggest that active/exploratory training fosters the enhancement of meta-cognitive skills, such as planning, monitoring, or evaluation of goals and strategies. It will be a promising avenue for future research to examine if active/exploratory training also has beneficial effects on proactive behaviour.

\section{APPLYING PROACTIVITY IN A GLOBAL CONTEXT}

Work has never been as "international" as now. Not only is the number of internationally operating corporations increasing, international migration is also on the rise. Thus, understanding cross-cultural differences in proactive behaviours is a timely topic. This is not only interesting with respect to theory development, but also from the perspective of Human Resource Management practices. Whenever a multinational firm chooses an ethnocentric strategy regarding their people management practices by applying the head office practices - including assessment instruments - to the subsidiaries, this raises the vested question of whether the people management practices will also be effective "over there" (Dowling \& Welch, 2004). Thus, the question of generalisability of findings on proactive behaviours becomes imperative: Are methods of assessment applicable worldwide? And can we transfer findings on antecedents and consequences from the cultural context in which they have been identified to other cultural settings? We explore these questions by presenting a cursory look at the proactive behaviour research from a "global" perspective.

So far, the majority of research on proactive behaviours has been performed in Europe and North America. The PI construct, for example, was first developed in Germany, assessed with both interview and a questionnaire measure (Frese, Fay, Hilburger, Leng, \& Tag, 1997; Frese, Garst et al., 2007; Frese et al., 1996). Today, the questionnaire-based personal initiative measure is not only used in Germany (e.g. Binnewies, Ohly, \& Sonnentag, 2007; Ohly et al., 2006), but also in the Netherlands (Den Hartog \& Belschak, 2007; Salanova \& Schaufeli, 2008), Finland (Hakanen et al., 2008), Spain (Peiró, García-Montalvo, \& Gracia, 2002; Salanova \& Schaufeli, 2008), and the USA (Allen, Facteau, \& Facteau, 2004). Related constructs like taking charge, voice or proactive behaviours have been studied in the USA (Morrison \& Phelps, 1999), in the UK (Parker et al., 2006; Tucker, Chmiel, Turner, Hershcovis, \& Stride, 2008), and in Germany (Fritz \& Sonnentag, 2009). Research outside Europe and North America is steadily developing, for example in India (McAllister, Kamdar, Morrison, \& Turban, 2007; Van 
Dyne, Kamdar, \& Joireman, 2008), China (Si, Wei, \& Li, 2008), or Israel (Kurman \& Dan, 2007); and in their studies on small business owners, Stefanie Krauss and Michael Frese applied personal initiative in South Africa, Zimbabwe, and Namibia (Frese, Krauss, Keith, Escher, Grabarkiewicz, Luneng, Heers, Unger, \& Friedrich, 2007; Krauss, Frese, Friedrich, \& Unger, 2005).

First insights regarding the above questions on cross-cultural differences can be derived from the study of mean differences between cultures. Cultural differences in value systems and interpretations may produce differences in work-related behaviour tendencies. Considering that proactive behaviours are to some extent challenging and change oriented, a culture's level of uncertainty avoidance (Hofstede, 2001) as well as its orientation towards conservatism (Schwartz, 1999) are likely to affect levels of proactive behaviours (see also Rank, Pace, \& Frese, 2004). So far, only few studies have embarked on this way. Kurman and Dan (2007) explored personal initiative of students in Israel. They compared levels of initiative among Israeli-born Jewish students, Arab Israeli students and Ethiopian-born Jewish students, deriving their hypotheses from the differences in value systems between these populations. Confirming their hypothesis, they found Israeli-born Jewish students reporting higher levels of personal initiative than the other two groups of students.

Considering that proactive behaviour research takes place worldwide, and that there seems to be interest in cross-cultural comparison, it's high time to establish the cross-cultural validity of assessment methods for proactive behaviours. Measurement equivalence (van der Vijver \& Leung, 1997) and acceptance (Ryan, Boyce, Ghumman, Jundt, Schmidt, \& Gibby, 2009) of the assessment instruments across different cultures needs to be investigated. While a superficial look at the above-cited studies suggests that the different measures provided reasonable internal consistencies, a systematic exploration of measurement equivalence has yet to be performed. The next step would entail an exploration of structural equivalence, by exploring whether (or in which cultures) proactive behaviour is related to desirable performance outcomes. What makes us optimistic about the cultural independence of proactive behaviour is research on small business owners. Frese and Krauss demonstrated with samples of small business owners in various African countries that personal initiative, conceptualised as a motivational resource or treated as an aspect of entrepreneurial orientation, was related to business outcomes (Frese, Krauss et al., 2007; Krauss et al., 2005); the business owner's personal initiative was also found to be important for business success in a sample of German firms (Zempel, 1999).

We do, however, need to point out that what we request for proactive behaviours has not yet even been achieved for more established performance assessment methods and procedures. So far, much evidence for the interna- 
tional generalisability of criterion-related validity has been accumulated for cognitive ability (Salgado, Anderson, Moscoso, \& de Fruyt, 2003) and personality tests (Salgado, 1997); but there are still substantial research gaps. Banki and Latham (2010, this issue) studied the situational judgement test and the situational interview in Iran, and found that they were both related to job performance.

Going beyond cross-cultural differences in levels of proactive behaviours would be the exploration of culture-dependent patterns of relationships. A cursory look at the proactive behaviour research suggests some informative cross-cultural commonalities. On the predictor side, job resources like job control are related to (or predict) proactive behaviours in Spain (Salanova \& Schaufeli, 2008), Germany (Frese, Garst et al., 2007), and the UK (Parker et al., 2006). Commonalities on the person side relate to self-efficacy (UK, USA, Germany) (Morrison \& Phelps, 1999; Parker et al., 2006; Speier \& Frese, 1997), positive affect (USA, Netherlands, Germany) (Allen et al., 2004; Den Hartog \& Belschak, 2007; Fritz \& Sonnentag, 2009), and engagement (Netherlands, Spain, Germany) (Salanova \& Schaufeli, 2008; Sonnentag, 2003). One study that tested the job resources-proactive behaviour link in samples from two countries-Spain and the Netherlands - showed strong similarity in the models in both countries, but there were also some differences in terms of the strengths of relationships between variables (i.e. the magnitude of the path coefficients differed) (Salanova \& Schaufeli, 2008). While these findings indicate considerable robustness of relationships across cultures, a systematic approach to cultural differences is timely. Considering that cultural differences are quite substantial even in countries with a shared history and close geographical proximity (Brodbeck, Frese, \& Javidan, 2002), the development and test of culturally dependent models is needed.

For example, depending on the specific nature of culture, proactive behaviours might need different types of support to unfold. While the work group's climate for proactivity might exert a strong influence on individual proactive behaviours in collectivistic cultures, this effect might be less strong in individualistic cultures. Similarly, in cultures with short-term orientation the supervisor's level of visionary leadership might have a stronger effect on individual proactivity in comparison to cultures with long-term orientation.

\section{CONCLUSION}

In this paper we have argued that the area of discretionary work behaviour offers promising avenues for future research. While past efforts focused on "construct clean-up" (Organ, 1997) and at identifying predictors and outcomes of proactive performance, $\mathrm{OCB}$, and other forms of discretionary work behaviour, we suggested enlarging the scope in terms of time frames studied, the degree of active interventions (as opposed to passive observa- 
tions), and geographic areas. These new research topics to be addressed partially seek specific methodological approaches including multi-level analysis (Beal \& Weiss, 2003), modelling growth trajectories (Bliese \& Ployhart, 2002), and methods of cross-cultural psychology (Gelfand, Erez, \& Aycan, 2007). Although the directions proposed in this paper are not completely new, we hope and expect that pursuing them will keep research on discretionary work behaviour a vibrant field within applied psychology and organisational behaviour.

\section{REFERENCES}

Aguinis, H., \& Kraiger, K. (2009). Benefits of training and development for individuals and teams, organizations, and society. Annual Review of Psychology, 60, 451-474.

Allen, T.D. (2006). Rewarding good citizens: The relationship between citizenship behavior, gender, and organizational rewards. Journal of Applied Social Psychology, 36, 120-143.

Allen, T.D., Facteau, J.D., \& Facteau, C.L. (2004). Structured interviewing for OCB: Construct validity, faking, and the effects of question type. Human Performance, 17, 1-24.

Ashford, S.J., \& Black, J.S. (1996). Proactivity during organizational entry: The role of desire for control. Journal of Applied Psychology, 81, 199-214.

Ashford, S.J., \& Cummings, L.L. (1983). Feedback as an individual resource: Personal strategies of creating information. Organizational Behavior and Human Performance, 32, 370-398.

Axtell, C.M., \& Parker, S.K. (2003). Promoting role breadth self-efficacy through involvement, work redesign and training. Human Relations, 56, 112-131.

Banki, S., \& Latham, G.P. (2010). The criterion-related validities and perceived fairness of the situational interview and the situational judgement test in an Iranian organization. Applied Psychology: An International Review, 59, 124-142.

Bateman, T.S., \& Crant, J.M. (1993). The proactive component of organizational behavior: A measure and correlates. Journal of Organizational Behavior, 14, 103118.

Beal, D.J., \& Weiss, H.M. (2003). Methods of ecological momentary assessment in organizational research. Organizational Research Methods, 6, 440-464.

Beal, D.J., Weiss, H.M., Barros, E., \& MacDermid, S.M. (2005). An episodic process model of affective influences on performance. Journal of Applied Psychology, 90, 1054-1068.

Bell, B.S., \& Kozlowski, S.W.J. (2008). Active learning: Effects of core training design elements on self-regulatory processes, learning, and adaptability. Journal of Applied Psychology, 93, 296-316.

Belschak, F.D., \& Den Hartog, D.N. (in press). Pro-self, prosocial, and proorganizational foci of proactive behaviour: Differential antecedents and consequences. Journal of Occupational and Organizational Psychology.

Berry, C.M., Ones, D.S., \& Sackett, P.R. (2007). Interpersonal deviance, organizational deviance, and their common correlates: A review and meta-analysis. Journal of Applied Psychology, 92, 410-424. 
Binnewies, C., Ohly, S., \& Sonnentag, S. (2007). Taking personal initiative and communicating about ideas: What is important for the creative process and for idea creativity? European Journal of Work and Organizational Psychology, 16, 432-455.

Binnewies, C., Sonnentag, S., \& Mojza, E.J. (2009). Daily performance at work: Feeling recovered in the morning as a predictor of day-level job performance. Journal of Organizational Behavior, 30, 67-93.

Bliese, P.D., \& Ployhart, R.E. (2002). Growth modeling using random coefficient models: Model building, testing, and illustrations. Organizational Research Methods, 5, 362-387.

Bond, F.W., \& Bunce, D. (2000). Mediators of change in emotion-focused and problem-focused worksite stress management interventions. Journal of Occupational Health Psychology, 5, 156-163.

Borman, W.C., \& Motowidlo, S.J. (1993). Expanding the criterion domain to include elements of contextual performance. In N. Schmitt \& W.C. Borman (Eds.), Personnel selection in organizations (pp. 71-98). San Francisco, CA: Jossey-Bass.

Brief, A.P., \& Motowidlo, S.J. (1986). Proscocial organizational behaviors. Academy of Management Review, 10, 710-725.

Brodbeck, F.C., Frese, M., \& Javidan, M. (2002). Leadership made in Germany: Low on compassion, high on performance. Academy of Management Executive, 16, $16-29$.

Campbell, D.J. (2000). The proactive employee: Managing workplace initiative. Academy of Management Executive, 14, 52-66.

Carstensen, L.L., Isaacowitz, D.M., \& Charles, S.T. (1999). Taking time seriously: A theory of socioemotional selectivity. American Psychologist, 54, 165-181.

Dalal, R.S. (2005). A meta-analysis of the relationship between organizational citizenship behavior and counterproductive work behavior. Journal of Applied Psychology, 90, 1241-1255.

de Lange, A.H., Taris, T.W., Kompier, M.A.J., Houtman, I.L.D., \& Bongers, P.M. (2003). "The very best of the millennium": Longitudinal research and the demandcontrol-(support) model. Journal of Occupational Health Psychology, 8, 282305.

Den Hartog, D.N., \& Belschak, F.D. (2007). Personal initiative, commitment and affect at work. Journal of Occupational and Organizational Psychology, 80, 601622.

Dowling, P.J., \& Welch, D.E. (2004). International human resource management. London: Thomson.

Fassina, N.E., Jones, D.A., \& Uggerslev, K.L. (2008). Relationship clean-up time: Using meta-analysis and path analysis to clarify relationships among job satisfaction, perceived fairness, and citizenship behaviors. Journal of Management, 34, 161-188.

Fay, D., \& Sonnentag, S. (2002). Rethinking the effects of stressors: A longitudinal study on personal initiative. Journal of Occupational Health Psychology, 7, 221234.

Fisher, C.D., \& Noble, C.S. (2004). A within-person examination of correlates of performance and emotions while working. Human Performance, 17, 145-168. 
Fox, S., Spector, P.E., \& Miles, D. (2001). Counterproductive work behavior (CWB) in response to job stressors and organizational justice: Some mediator and moderator tests for autonomy and emotions. Journal of Vocational Behavior, 59, 291-309.

Frayne, C.A., \& Geringer, J.M. (2000). Self-management training for improving job performance: A field experiment involving salespeople. Journal of Applied Psychology, 85, 361-372.

Frese, M. (2008). The word is out: We need an active performance concept for modern workplaces. Industrial and Organizational Psychology: Perspectives on Science and Practice, 1, 67-69.

Frese, M., \& Fay, D. (2001). Personal initiative: An active performance concept for work in the 21 st century. In B.M. Staw \& R.I. Sutton (Eds.), Research in organizational behavior (Vol. 23, pp. 133-187). Amsterdam: Elsevier.

Frese, M., Fay, D., Hilburger, T., Leng, K., \& Tag, A. (1997). The concept of personal initiative: Operationalization, reliability and validity in two German samples. Journal of Occupational and Organizational Psychology, 70, 139-161.

Frese, M., Garman, G., Garmeister, K., Halemba, K., Hortig, A., Pulwitt, T., \& Schildbach, S. (2002). Training zur Erhöhung der Eigeninitiative bei Arbeitslosen: Bericht über einen Pilotversuch [An intervention to increase personal initiative in the unemployed: A pilot study]. Zeitschrift für Arbeits- und Organisationspsychologie, 46, 89-97.

Frese, M., Garst, H., \& Fay, D. (2007). Making things happen: Reciprocal relationships between work characteristics and personal initiative in a four-wave longitudinal structural equation model. Journal of Applied Psychology, 92, 1084-1102.

Frese, M., Krauss, S.I., Keith, N., Escher, S., Grabarkiewicz, R., Luneng, S.T., Heers, C., Unger, J., \& Friedrich, C. (2007). Business owners' action planning and its relationship to business success in three African countries. Journal of Applied Psychology, 92, 1481-1498.

Frese, M., Kring, W., Soose, A., \& Zempel, J. (1996). Personal initiative at work: Differences between East and West Germany. Academy of Management Journal, $39,37-63$.

Frese, M., \& Zapf, D. (1994). Action as the core of work psychology: A German approach. In H.C. Triandis, M.D. Dunnette, \& L.M. Hough (Eds.), Handbook of industrial and organizational psychology (2nd edn., Vol. 4, pp. 271-340). Palo Alto, CA: Consulting Psychologists Press.

Fritz, C., \& Sonnentag, S. (2009). Antecedents of day-level proactive behavior: A look at job stressors and positive affect during the workday. Journal of Management, $35,94-111$

Gelfand, M.J., Erez, M., \& Aycan, Z. (2007). Cross-cultural organizational behavior. Annual Review of Psychology, 58, 479-514.

Griffin, B., \& Hesketh, B. (2008). Post-retirement work: The individual determinants of paid and volunteer work. Journal of Occupational and Organizational Psychology, 81, 101-121.

Griffin, M.A., Neal, A., \& Parker, S.K. (2007). A new model of work role performance: Positive behavior in uncertain and interdependent contexts. Academy of Management Journal, 50, 327-347. 
Hacker, W. (1986). Arbeitspsychologie [Work psychology]. Bern, Switzerland: Huber.

Hakanen, J.J., Perhoniemi, R., \& Toppinen-Tanner, S. (2008). Positive gain spirals at work: From job resources to work engagement, personal initiative and work-unit innovativeness. Journal of Vocational Behavior, 73, 78-91.

Hershcovis, M.S., Turner, N., Barling, J., Arnold, K.A., Dupré, K.E., Inness, M., LeBlanc, M., \& Sivanathan, N. (2007). Predicting workplace aggression: A metaanalysis. Journal of Applied Psychology, 92, 228-238.

Hoffman, B.J., Blair, C.A., Meriac, J.P., \& Woehr, D.J. (2007). Expanding the criterion domain? A quantitative review of the OCB literature. Journal of Applied Psychology, 92, 555-566.

Hofstede, G. (2001). Culture's consequences: Comparing values, behaviors, institutions and organizations across nations (2nd edn.). Thousand Oaks, CA: Sage Publications.

Hornung, S., \& Rousseau, D.M. (2007). Active on the job-proactive in change: How autonomy at work contributes to employee support for organizational change. Journal of Applied Behavioral Science, 43, 401-426.

Ilies, R., Nahrgang, J.D., \& Morgeson, F.P. (2007). Leader-member exchange and citizenship behaviors: A meta-analysis. Journal of Applied Psychology, 92, 269-277.

Ilies, R., Scott, B.A., \& Judge, T.A. (2006). The interactive effects of personal traits and experienced states on intraindividual patterns of citizenship behavior. Academy of Management Journal, 49, 561-575.

Kanfer, R., \& Ackerman, P.L. (2004). Aging, adult development, and work motivation. Academy of Management Review, 29, 440-458.

Kanfer, R., Wolf, M.B., Kantrowitz, T.M., \& Ackerman, P.L. (2010). Ability and trait complex predictors of academic and job permance: A person-situation approach. Applied Psychology: An International Review, 59, 40-69.

Karoly, P., \& Kanfer, F.H. (1982). Self-management and behaviour change: From theory to practice. Amsterdam: Elsevier.

Keith, N., \& Frese, M. (2008). Effectiveness of error management training: A metaanalysis. Journal of Applied Psychology, 93, 59-69.

Keith, N., Richter, T., \& Naumann, J. (2010). Active/exploratory training promotes transfer even in learners with low motivation and cognitive ability. Applied Psychology: An International Review, 59, 97-123.

Kirby, E.G., Kirby, S.L., \& Lewis, M.A. (2002). A study of the effectiveness of training proactive thinking. Journal of Applied Social Psychology, 32, 15381549.

Koys, D.J. (2001). The effects of employee satisfaction, organizational citizenship behavior, and turnover on organizational effectiveness: A unit-level, longitudinal study. Personnel Psychology, 54, 101-114.

Krauss, S.I., Frese, M., Friedrich, C., \& Unger, J.M. (2005). Entrepreneurial orientation: A psychological model of success among southern African small business owners. European Journal of Work and Organizational Psychology, 14, 315-344.

Kurman, J., \& Dan, O. (2007). Unpackaging cross-cultural differences in initiation between Israeli subgroups: Tradition and control orientations as mediating factors. Journal of Cross-Cultural Psychology, 38, 581-594. 
Latham, G.P., \& Frayne, C.A. (1989). Self-management training for increasing job attendance: A follow-up and a replication. Journal of Applied Psychology, 74, 411-416.

LePine, J.A., Erez, A., \& Johnson, D.E. (2002). The nature and dimensionality of organizational citizenship behavior: A critical review and meta-analysis. Journal of Applied Psychology, 87, 52-65.

LePine, J.A., \& Van Dyne, L. (1998). Predicting voice behavior in work groups. Journal of Applied Psychology, 83, 853-868.

McAllister, D.J., Kamdar, D., Morrison, E.W., \& Turban, D.B. (2007). Disentangling role perceptions: How perceived role breadth, discretion, instrumentality, and efficacy relate to helping and taking charge. Journal of Applied Psychology, 92, $1200-1211$.

Morrison, E.W., \& Phelps, C.C. (1999). Taking charge at work: Extrarole efforts to initiate workplace change. Academy of Management Journal, 42, 403419.

Ohly, S., Sonnentag, S., \& Pluntke, F. (2006). Routinization, work characteristics and their relationships with creative and proactive behaviors. Journal of Organizational Behavior, 27, 257-279.

Organ, D.W. (1988). Organizational citizenship behavior: The good soldier syndrome. Lexington, MA: Lexington Books.

Organ, D.W. (1997). Organizational citizenship behavior: It's construct clean-up time. Human Performance, 10, 85-97.

Parker, S.K., Wall, T.D., \& Jackson, P.R. (1997). "That's not my job": Developing flexible employee work orientations. Academy of Management Journal, 40, 899929.

Parker, S.K., Williams, H.M., \& Turner, N. (2006). Modelling the antecedents of proactive behavior at work. Journal of Applied Psychology, 91, 636-652.

Peiró, J., García-Montalvo, J., \& Gracia, F. (2002). How do young people cope with job flexibility? Demographic and psychological antecedents of the resistance to accept a job with non-preferred flexibility features. Applied Psychology: An International Review, 51, 43-66.

Podsakoff, N.P., LePine, J.A., \& LePine, M.A. (2007). Differential challenge stressorhindrance stressor relationships with job attitudes, turnover intentions, turnover, and withdrawal behavior: A meta-analysis. Journal of Applied Psychology, 92, 438-454.

Podsakoff, N.P., Whiting, S.W., Podsakoff, P.M., \& Blume, B.D. (2009). Individualand organizational-level consequences of organizational citizenship behaviors: A meta-analysis. Journal of Applied Psychology, 94, 122-141.

Podsakoff, P.M., Ahearne, M., \& MacKenzie, S.B. (1997). Organizational citizenship behavior and the quantity and quality of work group performance. Journal of Applied Psychology, 82, 262-270.

Raabe, B., Frese, M., \& Beehr, T.A. (2007). Action regulation theory and career self-management. Journal of Vocational Behavior, 70, 297-311.

Rank, J., Carsten, J.M., Unger, J.M., \& Spector, P.E. (2007). Proactive customer service performance: Relationships with individual, task, and leadership variables. Human Performance, 20, 363-390. 
Rank, J., Pace, V.L., \& Frese, M. (2004). Three avenues for future research on creativity, innovation, and initiative. Applied Psychology: An International Review, $53,518-528$.

Rioux, S.M., \& Penner, L.A. (2001). The causes of organizational citizenship behavior: A motivational analysis. Journal of Applied Psychology, 86, 13061314.

Rotundo, M., \& Sackett, P.R. (2002). The relative importance of task, citizenship, and counterproductive performance to global ratings of job performance: A policy-capturing approach. Journal of Applied Psychology, 87, 66-80.

Ryan, R.M., Boyce, A.S., Ghumman, S., Jundt, D., Schmidt, G., \& Gibby, R. (2009). Going global: Cultural values and perceptions of selection procedures. Applied Psychology: An International Review, 58, 520-556.

Sackett, P.R. (2002). The structure of counterproductive work behaviors: Dimensionality and relationships with facets of job performance. International Journal of Selection and Assessment, 10, 5-11.

Salanova, M., \& Schaufeli, W.B. (2008). A cross-national study of work engagement as a mediator between job resources and proactive behaviour. International Journal of Human Resource Management, 19, 116-131.

Salgado, J.F. (1997). The five factor model of personality and job performance in the European Community. Journal of Applied Psychology, 82, 30-43.

Salgado, J.F., Anderson, N., Moscoso, S., \& de Fruyt, F. (2003). International validity generalization of GMA and cognitive abilities: A European community meta-analysis. Personnel Psychology, 56, 573-605.

Schmidt, F.L., \& Kaplan, L.B. (1971). Composite vs. multiple criteria: A review and resolution of the controversy. Personnel Psychology, 24, 419-434.

Schwartz, S.H. (1999). A theory of cultural values and some implications for work. Applied Psychology: An International Review, 48, 23-47.

Searle, B.J. (2008). Does personal initiative training work as a stress management intervention? Journal of Occupational Health Psychology, 13, 259-270.

Semmer, N.K., Tschan, F., Meier, L.L., Facchin, S., \& Jacobshagen, N. (2010). Illegimate tasks and counterproductive work behavior. Applied Psychology: An International Review, 59, 70-123.

Si, S.X., Wei, F., \& Li, Y. (2008). The effect of organizational psychological contract violation on managers' exit, voice, loyalty and neglect in the Chinese context. International Journal of Human Resource Management, 19, 932-944.

Skarlicki, D.P., \& Folger, R. (1997). Retaliation in the workplace: The roles of distributive, procedural, and interactional justice. Journal of Applied Psychology, $82,434443$.

Smith, C.A., Organ, D.W., \& Near, J.P. (1983). Organizational citizenship behavior: Its nature and antecedents. Journal of Applied Psychology, 68, 653-663.

Sonnentag, S. (2003). Recovery, work engagement, and practice behavior: A new look at the interface between nonwork and work. Journal of Applied Psychology, 88, $518-528$.

Sonnentag, S., \& Frese, M. (2003). Stress in organisations. In W.C. Borman, D.R. Ilgen, \& R. Klimoski (Eds.), Handbook of psychology: Industrial and organizational psychology (Vol. XII, pp. 453-491). Hoboken, NJ: Wiley. 
Spector, P.E., \& Fox, S. (2010). Counterproductive work behavior and organizational citizenship behavior: Are they opposite forms of active behavior? Applied Psychology: An International Review, 59, 21-39.

Speier, C., \& Frese, M. (1997). Generalized self-efficacy as a mediator and moderator between control and complexity at work and personal initiative: A longitudinal field study in East Germany. Human Performance, 10, 171-192.

Stampler, C.L., \& Van Dyne, L. (2001). Work status and organizational citizenship behavior: A field study of restaurant employees. Journal of Organizational Behavior, 22, 517-536.

Super, D.E. (1990). A life-span, life-space approach to career development. In D. Brown \& L. Brooks (Eds.), Career choice and development: Applying contemporary theories to practice (2nd edn., pp. 197-261). San Francisco, CA: Jossey-Bass.

Tornau, K., \& Frese, M. (2009). The nomological net of proactivity: A meta-analytic investigation. Unpublished manuscript.

Trougakos, J.P., Beal, D.J., Green, S.G., \& Weiss, H.M. (2008). Making the break count: An episodic examination of recovery activities, emotional experiences, and positive affective displays. Academy of Management Journal, 51, 131-146.

Tucker, S., Chmiel, N., Turner, N., Hershcovis, M.S., \& Stride, C.B. (2008). Perceived organizational support for safety and employee safety voice: The mediating role of coworker support for safety. Journal of Occupational Health Psychology, 13, 319-330.

van der Vijver, R.J.R., \& Leung, K. (1997). Methods and data analysis of comparative research. In L.W. Berry, Y.H. Poortinga, \& J. Pandey (Eds.), Handbook of cross-cultural psychology (2nd edn., Vol. 1, pp. 257-300). Boston, MA: Allyn and Bacon.

Van Dyne, L., Cummings, L.L., \& Parks, J.M. (1995). Extra-role behaviors: In pursuit of construct and definition clarity. Research in Organizational Behavior, 17, 215-285.

Van Dyne, L., Kamdar, D., \& Joireman, J. (2008). In-role perceptions buffer the negative impact of low LMX on helping and enhance the positive impact of high LMX on voice. Journal of Applied Psychology, 93, 1195-1207.

Van Dyne, L., \& LePine, J.A. (1998). Helping and voice extra-role behaviors: Evidence of construct and predictive validity. Academy of Management Journal, 41, $108-119$.

van Veldhoven, M., \& Dorenbosch, L. (2008). Age, proactivity and career development. Career Development International, 13, 112-131.

Warr, P. (2008). Work values: Some demographic and cultural correlates. Journal of Occupational and Organizational Psychology, 81, 751-775.

Zempel, J. (1999). Selbstaendigkeit in den neuen Bundeslaendern: Praediktoren, Erfolgsfaktoren und Folgen-Ergebnisse einer Laengsschnittuntersuchung [Selfemployment in the New German States: Predictors, success factors and consequences - results of a longitudinal study]. In K. Moser, B. Batinic, \& J. Zempel (Eds.), Unternehmerisch erfolgreiches Handeln (pp. 69-91). Goettingen: Hogrefe. 